\title{
Encantado de Filipe Galvon: O retrato de um presente que nunca passará?
}

\author{
Mélanie Toulhoat
}

Filipe Galvon (dir.) (2018/2020) Encantado. O Brasil em Desencanto. La Clairière Ouest/Public Sénat/Vosges Télévisions: França, 56/83 minutos. Filme documentário, Formato HDV 16/9.

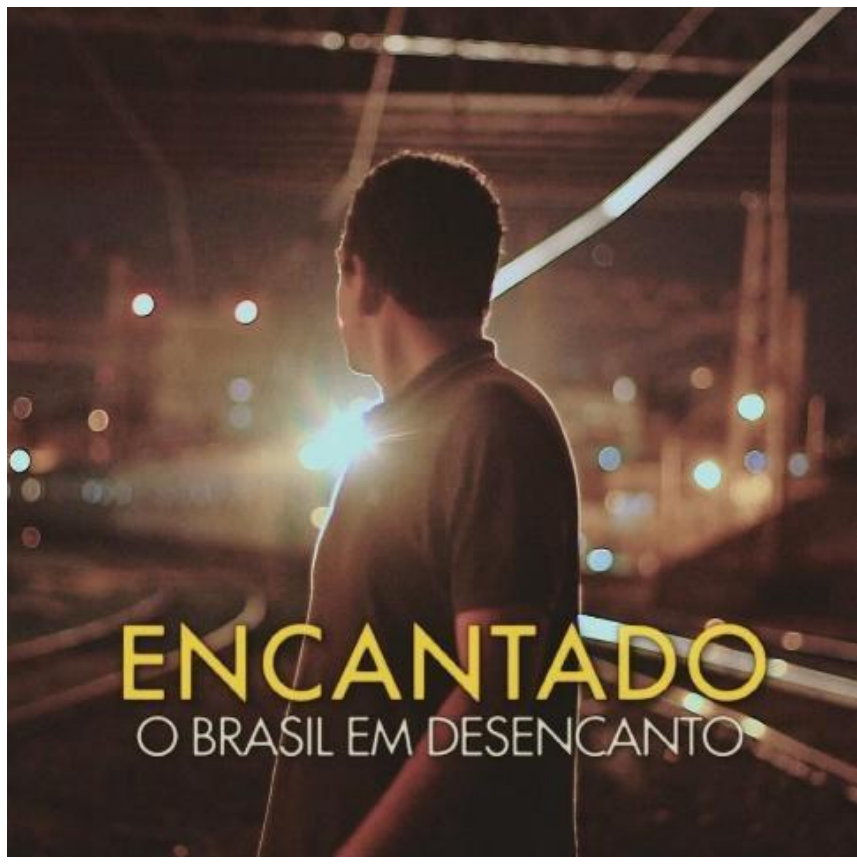

Figura: Capa do filme Encantado, reprodução autorizada pelo diretor

O filme Encantado começou a brotar em 2012, a partir de um projeto de Filipe Galvon, seu diretor. $\mathrm{O}$ objetivo inicial era documentar suas origens e a realidade de um bairro suburbano carioca de onde ele veio, um local popular que foi gradualmente abandonado pelas autoridades e até mesmo por seus próprios habitantes. Sob o olhar do Galvon, o Encantado se transformou aos poucos numa espécie de observatório das transformações e evoluções vividas no Brasil inteiro a partir de 2013.

À medida que os enormes protestos de junho 2013 aconteceram, parando o país inteiro, o projeto de filme tomou um rumo diferente. Tratava-se agora de analisar a transição de manifestações e expressões políticas inicialmente populares, não partidárias, até um conservadorismo desenfreado e a exacerbação de conflitos enraizados em uma sociedade extremamente desigual. Os grandes eventos de 2013 merecem ainda ser amplamente 
analisados em toda sua complexidade e na diversidade de suas questões, para que se possa compreender a história recente do país.

Filipe Galvon nasceu em 1981 e cresceu no Encantado, um bairro operário situado entre Madureira e Méier, zona norte do Rio de Janeiro. Com formação em jornalismo, ele desenvolveu atividades audiovisuais e literárias, tendo realizado seus primeiros curtametragens a partir de 2005. Autor de dez curtas produzidos entre 2006 e 2016, ele costuma brincar com os estilos e as práticas, misturando documentário e ficção para retratar o Brasil contemporâneo. Durante o ano 2013, ele viajou para França e fez estudos cinematográficos na Universidade de Paris. O filme anuncia esse ponto de vista desde o início, como se quisesse sublinhar os desafios, a carga simbólica e o lugar de fala a ele associados: "Ce film a été réalisé par un brésilien qui habite en France depuis 2013". O diretor pertence de fato à primeira geração brasileira oriunda das classes populares que teve acesso a possibilidades e incentivos para poder estudar no exterior e fazer intercâmbios, durante os governos do Partido dos Trabalhadores (PT) na era Lula-Dilma.

Em 2016, ele participou na França da criação do Movimento Democrático de 18 de março (MD-18), comprometido com a defesa da democracia constitucional no Brasil e contra a destituição da presidenta Dilma Rousseff. A trajetória pessoal engajada de Galvon, num contexto político crítico a partir dos anos 2010 no Brasil, conduz gradualmente seu cinema fictício a um cinema politicamente comprometido, profundamente ligado à defesa da democracia em seu país. No entanto, ele mesmo define a diferença fundamental entre um cinema comprometido e um cinema partidário, um cinema de propaganda política, do qual ele deseja se distanciar: seu objetivo é "tentar mostrar em vez de dizer"1", a fim de permitir ao público espectador formar sua própria opinião sobre os fatos, eventos e aventuras que analisa em suas obras.

Através dos olhos do diretor, o filme propõe uma visão do desencantamento identificado no povo brasileiro, mas também nas lideranças e instituições, e insiste no aspecto geracional de uma juventude agora sem ilusões. Em uma sutil mistura de imagens de arquivo, entrevistas com moradores do Encantado, líderes políticos e figuras de destaque na vida política brasileira, imagens da cidade do Rio de Janeiro, palavras e testemunhos de brasileiras e brasileiros morando na França, e comentários do diretor, falando na primeira pessoa do singular e do plural, a obra alterna entre temporalidades e volta constantemente às múltiplas percepções escondidas por trás da polissemia do termo "encantado". No momento do lançamento virtual do filme realizado pela plataforma pública de divulgação

1 Ver a entrevista dele realizada em 2019 pelo MediaLab da Universidade Católica de Lille : https://www.youtube.com/watch?v= oc3coC4p3U. 
do conhecimento histórico "História da Ditadura", o próprio Filipe mencionou a imensa ironia do termo que se tornou o título do seu trabalho: "não é uma piada, tal vez uma piada pronta $^{2 \prime \prime}$.

Neste sentido, a construção do filme e as escolhas semânticas e visuais feitas não negligenciam este aspecto irônico e dramático da tragédia brasileira dos últimos anos. Isso ocorre por meio do uso de metáforas e metonímicas entre o bairro do Encantado e o Brasil, mas também de uma identificação muito forte do diretor, de sua geração e de seu país com os dramas e acontecimentos desse bairro fronteiriço, um bairro em movimento entre o progresso e os retrocessos, um bairro sintomático. O termo polissêmico refere-se ao encantamento político e à emoção de toda uma geração nascida após a ditadura militar (1964-1985) ou durante a transição democrática, que testemunhou a eleição de Lula no início dos anos 2000. A primeira parte do filme olha para trás, o período de ascensão do Brasil, tanto no plano doméstico como internacional, durante uma década que também corresponde a um momento progressista na região latino-americana.

A natureza documental do filme permite, até certo ponto, multiplicar as pessoas entrevistadas a fim de questionar as responsabilidades e as possibilidades de ação das brasileiras e dos brasileiros morando no exterior, testemunhas, agentes sociais, de fato distantes das mudanças sociais, políticas, geográficas e culturais do Brasil. É sempre possível imaginar que uma maior diversidade de pontos de vista teria permitido ao diretor abordar as questões brasileiras contemporâneas de um ângulo mais fundamentado, analisando assim as razões do desencanto de setores mais amplos da sociedade.

Porém, esse ângulo é também uma plataforma para mostrar e analisar as dificuldades em curso na época, as desigualdades ainda presentes sob os governos do PT, os enormes problemas ligados às obras faraônicas organizadas para sediar a Copa do Mundo de Futebol no país em 2014 e os Jogos Olímpicos no Rio de Janeiro em 2016. Em suma, o filme mostra progressivamente o preço a ser pago pelas promessas quebradas, pelas decepções e pelos excessos da esquerda no poder, pelo uso por grupos conservadores - em particular pela grande mídia brasileira - da raiva e do ressentimento acumulados, de um lado pelos setores mais desfavorecidos e, de outro, pelas elites que nunca aceitaram uma diminuição relativa da desigualdade.

O filme é uma tentativa de identificar as diversas e complexas razões de um desencanto tão amplo: a acomodação da esquerda no poder, o abandono das classes trabalhadoras, a prevalência do ultraconservadorismo, os efeitos da crise econômica global

\footnotetext{
${ }^{2}$ Ver o vídeo do lançamento: https://www.youtube.com/watch?v=dJ2ZmfymGE0.
} 
e a reação epidérmica dos setores mais ricos e privilegiados da sociedade brasileira, diante do fim do ciclo econômico extremamente virtuoso que caracterizou os governos do Presidente Lula. Um ódio visceral aos setores sociais e políticos progressistas também ganhou de novo um peso crescente no debate e no espaço públicos, em um país que está lutando para realizar um verdadeiro trabalho coletivo e público de memória e história sobre seu passado ditatorial muito recente, e cuja maquinaria econômica e grandes fortunas foram forjadas em grande parte através de séculos de escravidão.

Diante da suspensão de todas as conciliações, dos mecanismos em ação no Golpe de 2016, da impunidade das práticas autoritárias e da violência política, dos enganos acentuados, das conexões entre os movimentos evangélicos e o poder político, da fetichização de figuras políticas conservadoras, da manipulação da luta seletiva contra a corrupção, o filme relata algumas tentativas e alguns projetos para coordenar uma resposta partindo da França. Seria interessante estudar as razões da falta de impacto e da perda de impulso dessas ações políticas e culturais organizadas a partir do exterior desde a destituição presidencial de 2016, ações frequentemente oriundas de microcosmos urbanos da esquerda brasileira e internacional articulada e intelectualizada, apesar de uma diversidade real de perfis socioeconômicos e raciais.

Trata-se de compreender a batalha das narrativas conflitantes no jogo político. Neste sentido, a partir de uma perspectiva comparativa indispensável, o filme fala também sobre a França e sua reação (ou falta de reação) frente ao distanciamento dos setores populares do debate político, frente aos cortes drásticos no orçamento do setor público e, sobretudo, frente à ascensão ao poder de extrema direita autoritária, racista e criminosa. O filme Encantado, le Brésil désenchanté, foi transmitido em 2018 na França, no canal de televisão Public Sénat, coprodutor do projeto, apenas um mês antes das eleições presidenciais que permitiram a vitória de Jair Bolsonaro. Foi uma primeira versão, mais tarde retrabalhada e lançada em 2020 no Brasil, disponível na plataforma de download do Amazon Prime Video. Esta versão mais longa, destinada ao cinema, inclui o assassinato da vereadora Marielle Franco em março de 2018 e ganhou o Prêmio do Júri Popular de Melhor Filme no BIFF - Brasília Internacional Film Festival 2020. Filipe Galvon está se preparando para um lançamento próximo nas salas de cinema e uma difusão no Amazon Prime Video na Europa.

O filme não tem a pretensão de contar sozinho a história do Brasil de hoje, mas ele assume e oferece uma perspectiva original e sensível que, combinada com outras análises, pode sim contribuir para uma compreensão do presente do país e da região, questionando, em última instância, os significados profundos e complexos, mas também as fragilidades e falhas, dos regimes democráticos contemporâneos. 